International Journal of

Advanced Science and Convergence

\title{
Noise Energy Harvester: Analysis and classification of frequency produced by boat engine
}

\author{
Don C. Opada ${ }^{1}$, Elmer S. Maravillas ${ }^{2}$ and Chris Jordan G. Aliac ${ }^{3}$ \\ ${ }^{1}$ College of Computer Studies, Cebu Institute of Technology University, Cebu City, Philippines \\ ${ }^{2}$ College of Computer Studies, Cebu Institute of Technology University, Cebu City, Philippines \\ ${ }^{3}$ College of Computer Studies, Cebu Institute of Technology University, Cebu City, Philippines
}

\begin{abstract}
Background/Objectives: A resonator plays a significant part in harnessing sound waves. An idea to use a resonator that only resonates on a specific frequency is hypothesized to harness sound efficiently. The primary objective of this study is to investigate the noise present in the boat engine room and be able to classify its resonant frequency and to know which of these frequencies occur most often. Methods/Statistical analysis: By using a sound recorder and a sound pressure level meter, the sound recorded from the idle state of the boat to disembarking and upon reaching the destination. Findings: Fast Fourier transform is applied to extract the frequencies of the recorded sound. Then the frequencies are evaluated using the Davies-Bouldin index to estimate the number of clusters and K-means clustering to classify the frequencies. Improvements/Applications: There are 2 clusters found and that Cluster 1 frequencies are from $17 \mathrm{~Hz}$ to $3295 \mathrm{~Hz}$. Cluster 2 frequencies are from $6291 \mathrm{~Hz}$ to $8279 \mathrm{~Hz}$. Among the available frequencies, $47 \mathrm{~Hz}, 155 \mathrm{~Hz}$, and $186 \mathrm{~Hz}$ out weight all of the frequencies in terms of their occurrence, and among the three frequencies, $186 \mathrm{~Hz}$ has the highest amplitude.
\end{abstract}

\section{Index Terms}

Digital Signal Processing; Frequency Clustering; Noise Classification; Sound Analytics; Sound to Energy

\author{
Corresponding author: D.C. Opada \\ donopada@yahoo.com \\ - Manuscript received February 24, 2020 \\ - Revised March 15, 2020 ; Accepted March 20, 2020 \\ - Date of publication March 31, 2020 \\ (C) The Academic Society of Convergence Science Inc. \\ 2619-8150 ( 2019 IJASC. Personal use is permitted, but republication/redistribution requires IJASC permission.
}




\section{INTRODUCTION}

The demand for technology has become vital with the increase in population and sophisticated society. However, pollution is also caused by producing and using the same technologies humans have invented. To address the issues, a group of researchers conducted several studies in utilizing and recycling unwanted by-products, such as noise [1, 2]. According to the U.S. Department of Health and Human Services, rising noise levels can have a negative impact on human health. A sound of over $85 \mathrm{~dB}$ can cause permanent damage to one's hearing[3]. Marine activities, such as shipping and energy exploration, alter marine animals' ability to communicate, navigate, and hunt, to name a few. This study focuses on processing and analyzing the sound produced inside a boat engine room. The result of this study help in the design of a Noise Energy Harvester that efficiently harnesses unwanted noise and converts it to electricity for sustainable development.

Several studies of harvesting sound energy and used in different applications conducted. In a study conducted by Bacosa and Baldovino, they used a microphone to harness sound in a different noisy environment and used to charge a power bank[1]. Another study [2] utilized noise by using a piezoelectric material in lighting 1 led street lamp. The study [4] explored the use of a speaker and a transformer to convert noise produced by a car horn into electrical energy. Their studies utilized a transducer to convert sound energy into electricity. A transducer is a device that converts energy from one form to another[5]. According to Gupta, Goel, and Yadav, the efficiency of the transducers and several such devices is quite low and cannot utilize for practical applications[6]. The output power is just enough for low power applications like charging batteries and lighting a single LED. But when a transducer excited by its resonant frequency, it can generate high voltage output, as can be seen in the study of Fang, Hassan, Rahim, Isa, and Ismail [7].

Resonance is the tendency of a system to oscillate with higher amplitude at some frequencies than of others. Frequencies at which the response amplitude is a relative maximum are known as the system's resonant frequencies or resonance frequencies. At these frequencies, even small periodic driving forces can produce large amplitude oscillations, because the system stores vibrational energy[8]. A resonator plays a significant part in harnessing sound waves. The resonator sensors are mechanical modifiers in which an elastic element is excited into vibration at its natural frequency, the value of which depends on the desired input quantity, e.g., force or pressure[9], see Fig 1.

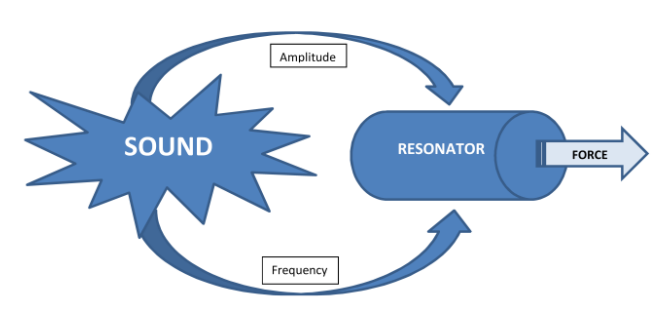

Fig. 1. Resonator sensor

To effectively and efficiently harness sound, we need to know the different frequencies a sound source produces, classify these frequencies and be able to know which frequencies occur most often.

A sound from a running engine varies from its displacement, condition, and location where it installed. It produces different resonant frequency, amplitude, and sound pressure level. The primary objective of this study is to investigate the noise present in the engine room of 869 tons capacity selfpropelling barge powered by two 600 HP euro 4 diesel engines and be able to classify their resonant frequency to know in what state that these frequencies occurs and which of these frequencies occurs most often.

\section{Materials AND Methods}

\section{A. Materials}

Data gathered by using a sound recorder Sony ICD-PX240 and a sound pressure level (SPL) meter Tondaj SL-814. Protective gear needed since the sound pressure level inside an engine room may reach the threshold of pain, which is above $130 \mathrm{~dB}$ and can cause permanent hearing damage. Sound collected from the idle state of the boat to disembarking and upon reaching the destination. The sound recorder and SPL meter placed inside the engine room, see Fig. 2.

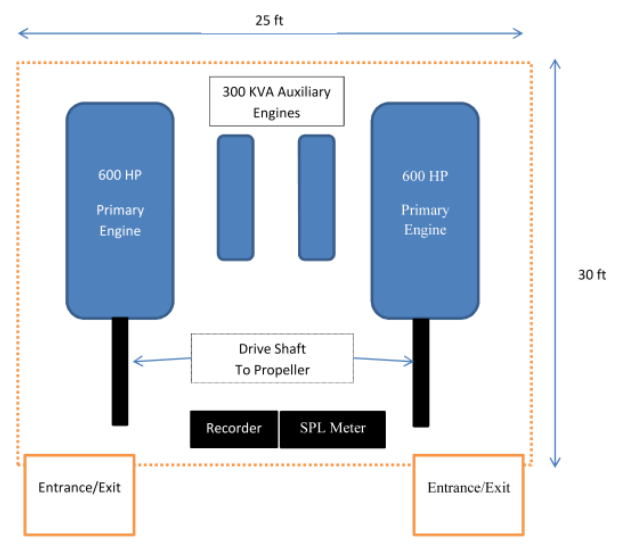

Fig. 2. Engine room setup 


\section{B. Methods}

Since the main objective of this study is to know the frequency that occurs most often and when the frequency is available. The method divided into two, conversion and classification, and analysis of frequency. The recorded sound is then processed using computing software created in the Matlab platform.

\section{Conversion and Classification}

In Fig. 3 shows how the data processed in the method in conversion and classification of sound.

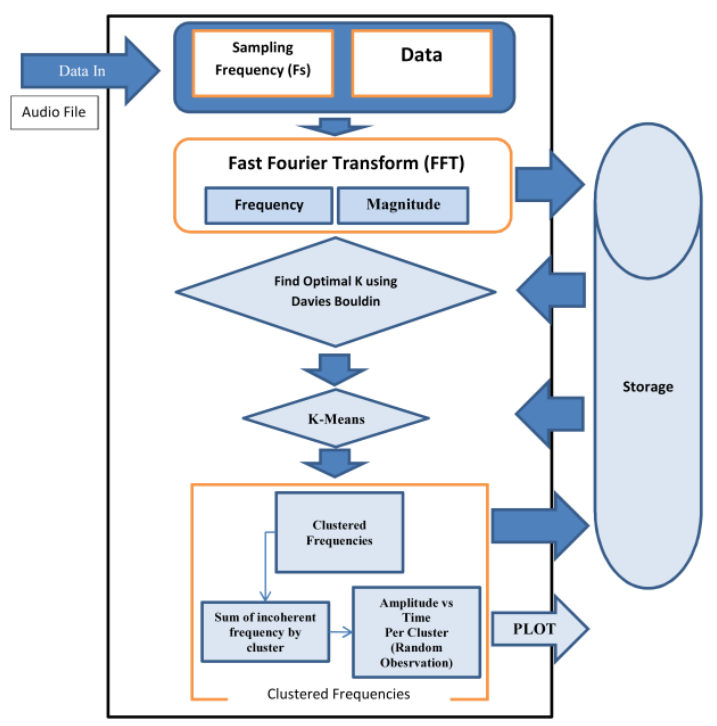

Fig. 3. Process in conversion and classification of frequency

Since this study focuses on the frequency, converting the time domain to the frequency domain is possible using a fast Fourier transform (FFT), and computed per second. The Fourier transform, or the analysis equation, is used[10]:

$$
\mathrm{Y}(\mathrm{k})=\sum_{j=1}^{n} \mathrm{X}(\mathrm{j}) \mathrm{W}_{n}^{(\mathrm{j}-1)(\mathrm{k}-1)}
$$

With a sampling frequency of $41000 \mathrm{~Hz}$, Frequency and magnitude are extracted per second using Matlab function FFT. All the frequencies (ALLFREQ) and the first 10 frequencies (HIGHFREQ) with high amplitude is then stored. The observations are processed repetitively.

Many studies used and implemented Fast Fourier transform and K-Means clustering in processing audio, the study $[11,12]$ identifies a person from the characteristic of voice. All the frequencies (ALLFREQ) be clustered using K-Means, but before clustering the frequencies, we need to estimate the number of cluster $K$. In the study of [13], used Davies Bouldin Index in determining the optimal number of cluster $K$. Using Matlab function evalclusters, ALLFREQ be evaluated to find the optimal K.

ALLFREQ in now clustered. We need to know the amplitude in a different scenario. Summing the amplitude using the incoherence formula gives us the amplitude per cluster versus time and we can visually

The equation below adds the incoherent signal level[14] $\mathrm{L}_{1}, \mathrm{~L}_{2} \ldots \mathrm{L}_{\mathrm{n}}$ and shows that adding sound pressure level is not just taking the summation of all magnitude of the sound wave.

$$
L_{\text {tot }}=10 \log _{10}\left(10^{\frac{L_{1}}{10}}+10^{\frac{L_{2}}{10}}+\cdots 10^{\frac{L_{n}}{10}}\right)
$$

Using observation and plot the data guide us visually on when will the clustered frequencies are available.

\section{Analysis of Frequency}

To be able to know which of the frequencies occurs most often, the clustered frequencies are further analyzed and process, see Fig. 4.

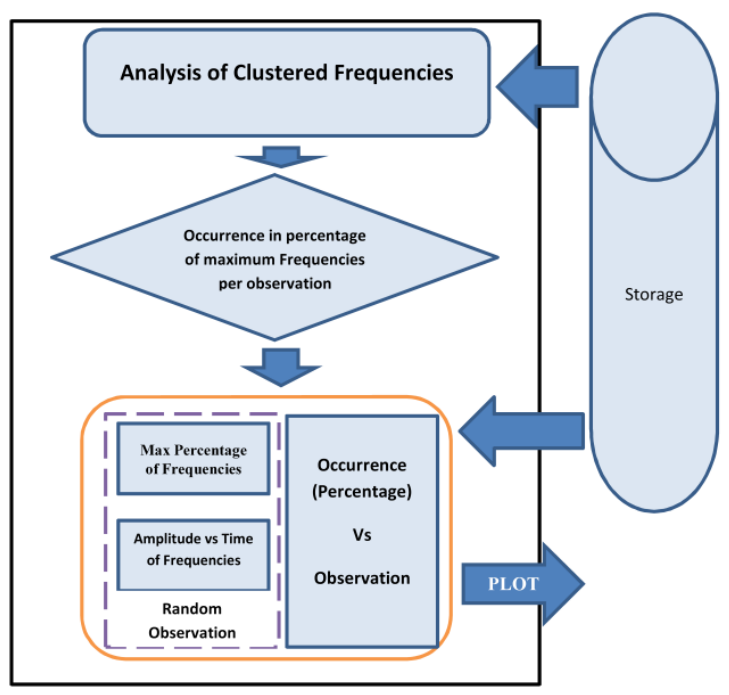

Fig. 4. A process on Analysis of Frequency

Frequencies HIGHFREQ is then retrieved from the storage and evaluated to find their percentage per occurrence of each frequency from all the observations and to find their means. Matlab function SORT is then used to sort the frequencies, which give us the occurrence of frequencies. Then divide it on the number of frequencies give us their percentage. Plot them guide us visually as to which frequency occurs more frequently.

Evaluating an observation and finding the frequencies that occur frequently help us see the performance of the frequencies. 


\section{RESUlt}

The boat in this study route is from Tampi Amlan, Negros Oriental to Bato Oslob, Province of Cebu, and vice versa. It took about $25-40$ minutes to travel. The recorded data was in $\mathrm{mp} 3$ format. There were 35 observations taken at different time and day, route, and different load the boat carries, see Table 1 . When the boat is in idle state, the sound pressure level inside the engine room reaches $103 \mathrm{~dB}$, and when the boat starts to disembark, the sound pressure level reaches up to $119 \mathrm{~dB}$ of sound pressures.

Table 1. Observations

\begin{tabular}{|c|c|c|c|c|c|}
\hline & Route & Load & Time & $\begin{array}{c}\text { Idle } \\
\text { SPL(dB) }\end{array}$ & $\begin{array}{c}\text { Sailing } \\
\text { SPL }(d B) \\
\end{array}$ \\
\hline 1 & Bato - Tampi & Full & 18:02 & 102.1 & 116.7 \\
\hline 2 & Tampi - Bato & Half & $20: 31$ & 100.6 & 114.1 \\
\hline 3 & Bato - Tampi & Full & $22: 30$ & 102.2 & 114.4 \\
\hline 4 & Tampi - Bato & Half & $4: 43$ & 99.8 & 112.3 \\
\hline 5 & Bato - Tampi & Full & $6: 43$ & 99.7 & 116.2 \\
\hline 6 & Tampi - Bato & Half & $9: 33$ & 99.1 & 110.8 \\
\hline 7 & Bato - Tampi & Half & $11: 36$ & 102.4 & 119.1 \\
\hline 8 & Tampi - Bato & Half & $13: 30$ & 106.3 & 113.1 \\
\hline 9 & Bato - Tampi & Half & $16: 00$ & 100.1 & 116.3 \\
\hline 10 & Tampi - Bato & Full & $19: 55$ & 100.7 & 110.1 \\
\hline 11 & Bato - Tampi & Half & $4: 39$ & 99.6 & 115.2 \\
\hline 12 & Tampi - Bato & Half & $8: 12$ & 100.2 & 115.6 \\
\hline 13 & Bato - Tampi & Half & $9: 33$ & 102.1 & 114.1 \\
\hline 14 & Tampi - Bato & Half & $11: 32$ & 106.2 & 111.7 \\
\hline 15 & Tampi - Bato & Full & $15: 32$ & 102.6 & 112.8 \\
\hline 16 & Bato - Tampi & Half & $16: 31$ & 102.8 & 113.7 \\
\hline 17 & Tampi - Bato & Half & $19: 45$ & 102.6 & 116.3 \\
\hline 18 & Bato - Tampi & Half & $21: 38$ & 104.5 & 118.7 \\
\hline 19 & Tampi - Bato & Full & $11: 43$ & 107.9 & 114.9 \\
\hline 20 & Bato - Tampi & Full & $12: 36$ & 103.5 & 114.1 \\
\hline 21 & Tampi - Bato & Half & $15: 10$ & 100.1 & 110.9 \\
\hline 22 & Bato - Tampi & Half & $17: 14$ & 99.3 & 110.1 \\
\hline 23 & Tampi - Bato & Full & 19:03 & 102.7 & 112.1 \\
\hline 24 & Bato - Tampi & Half & $20: 56$ & 100.4 & 117.2 \\
\hline 25 & Tampi - Bato & Full & $4: 59$ & 99.8 & 118.9 \\
\hline 26 & Bato - Tampi & Half & $6: 51$ & 99.3 & 116.7 \\
\hline 27 & Tampi - Bato & Half & $9: 19$ & 99.5 & 112.1 \\
\hline 28 & Tampi - Bato & Half & $13: 57$ & 103.7 & 119.2 \\
\hline 29 & Bato - Tampi & Half & $15: 49$ & 105.4 & 116 \\
\hline 30 & Bato - Tampi & Full & 20:05 & 117.5 & 112.3 \\
\hline 31 & Tampi - Bato & Full & 22:01 & 104.5 & 115.2 \\
\hline
\end{tabular}

\begin{tabular}{|r|l|l|r|r|r|}
32 & Bato - Tampi & Half & $23: 21$ & 99.6 & 113.8 \\
\hline 33 & Tampi - Bato & Full & $8: 35$ & 100.2 & 114.4 \\
\hline 34 & Bato - Tampi & Half & $10: 31$ & 103.5 & 118.1 \\
\hline 35 & Tampi - Bato & Full & $11: 46$ & 109.2 & 119.2 \\
\hline
\end{tabular}

After processing all the observations in method 1, the result show's two clustered frequencies. The clustered frequency range is as shown in Table 2.

Table 2. Clustered FREQUENCIES

\begin{tabular}{|c|c|}
\hline Cluster & Frequency Range in $\mathrm{Hz}$ \\
\hline 1 & $17-3295$ \\
\hline 2 & $6291-8279$ \\
\hline
\end{tabular}

By using the range of clustered frequencies in observation 1 with 3900 seconds, Fig. 5 shows the sum of amplitude per second of cluster 1 . In this cluster, the frequencies are always available from idle until it reaches the destination. These frequencies are less in amplitude during the travel.

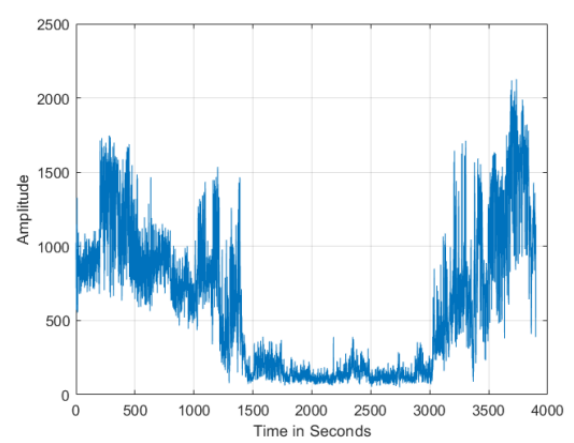

Fig. 5. The amplitude of Cluster 1 per second

Fig. 6. shows the sum of amplitude per second of cluster 2 . The frequencies are only present during sailing at 1401 seconds to 3022 seconds. In this observation, the boat sails 1621 seconds, around 27 minutes.

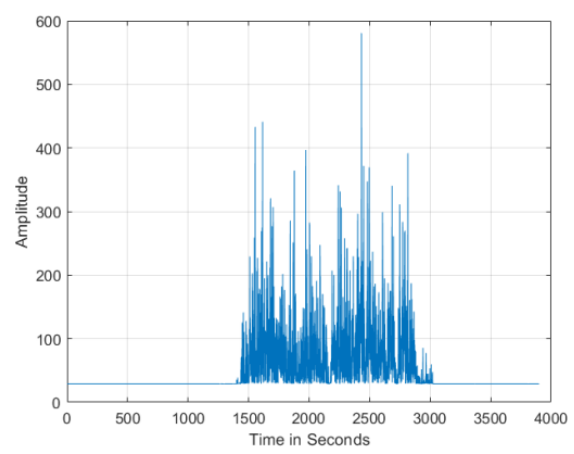

Fig. 6. The amplitude of Cluster 2 per second 


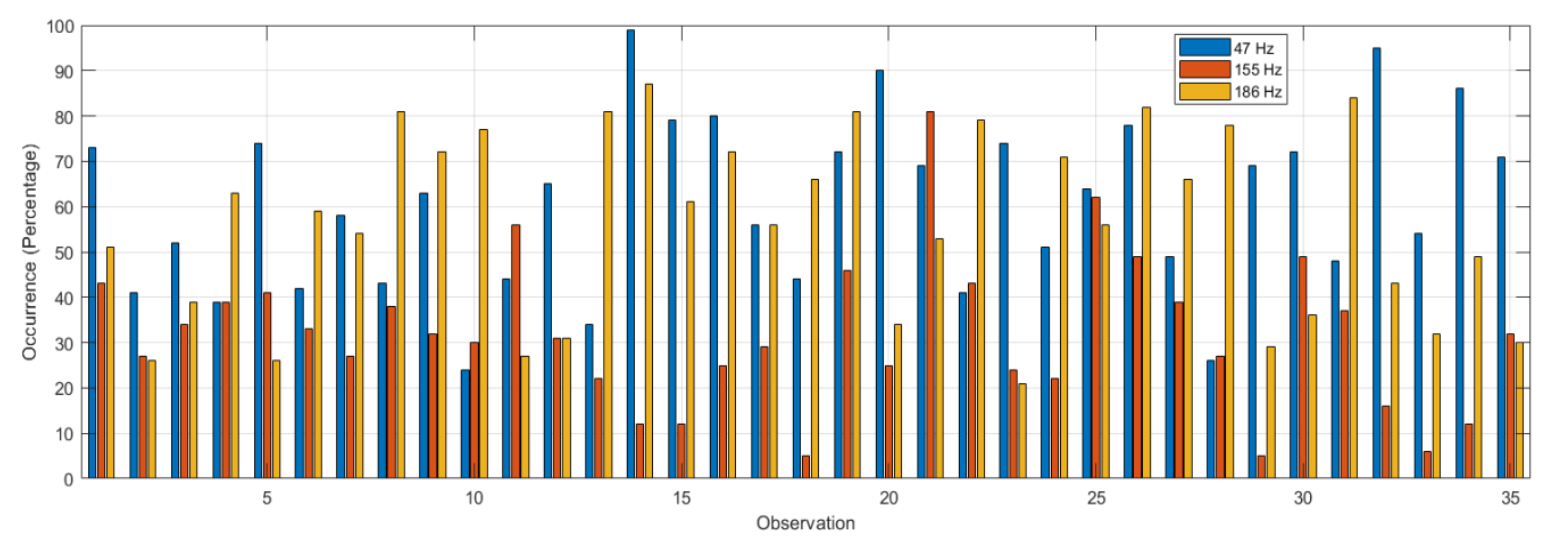

Fig. 7. Performance of Three Frequencies

Using method 2 from all of the observations, Table 3 shows the high amplitude frequency that occurs more frequently and their occurrence in percentage. From the 35 trips, $47 \mathrm{~Hz}, 155 \mathrm{~Hz}$, and $186 \mathrm{~Hz}$ occur more frequently. Fig. 7 shows the occurrence in the percentage of frequencies per observation.

Table 3. Frequencies

\begin{tabular}{|l|r|r|r|}
\hline Frequency $(\mathrm{Hz})$ & 47 & 155 & 186 \\
\hline Occurrence(Percentage) & 60.54 & 31.74 & 55.8 \\
\hline
\end{tabular}

The same observation is used and plotted to view the performance of each frequency. Fig. 8 shows the amplitude of the three frequencies with respect to time.
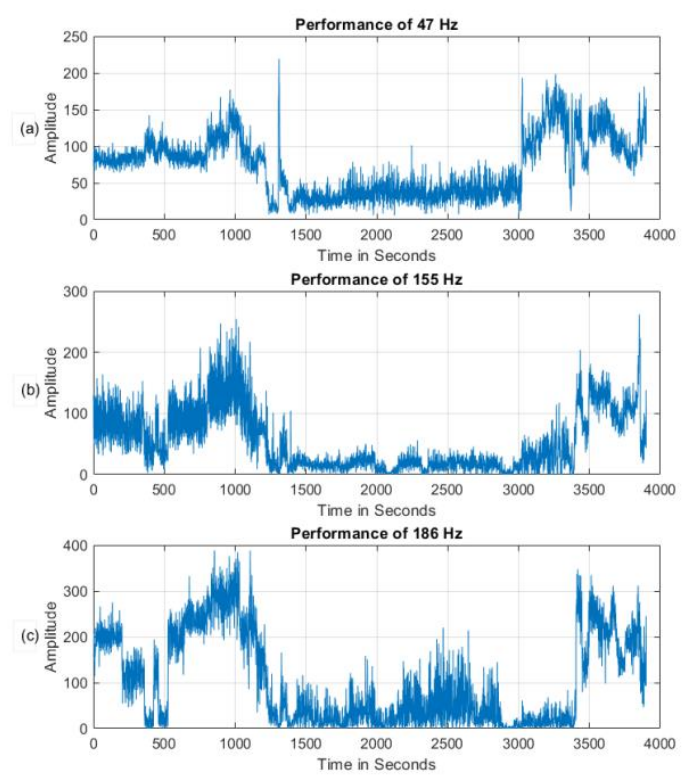

Fig. 8. Performance of Three Frequencies
Among the three frequencies, $186 \mathrm{~Hz}$ starts at high amplitude, see Fig. 8-c, but it's not stable since the amplitude drops low at around 400 seconds but has a high amplitude during sailing at 1401 seconds to 3022 compared to 47 and $155 \mathrm{~Hz}$. At time 3023 seconds, when the boat reaches its destination, its amplitude is low compared to the two frequencies but spike up around time 3350 seconds.

$155 \mathrm{~Hz}$ has a similar pattern of $186 \mathrm{~Hz}$, but its amplitude is much lower. Similarly, it's not stable and spikes up to around time 3350 seconds see Fig. 8-b.

Among all the three frequencies, $47 \mathrm{~Hz}$ is much stable though its amplitude is lower during travel time, see Fig. 8-a. But when the boat reaches its destination, it regains its amplitude.

\section{Discussion \& Conclusion}

The result shows the 2 groups of frequencies that are available inside the engine room. Cluster 1 frequencies are from $17 \mathrm{~Hz}$ to $3295 \mathrm{~Hz}$. Theses frequencies are always available from the idle state of the boat until it reaches the destination. Cluster 2 frequencies are from $6291 \mathrm{~Hz}$ to $8279 \mathrm{~Hz}$, and these frequencies are only present during sailing. Among the available frequencies, $47 \mathrm{~Hz}, 155 \mathrm{~Hz}$, and $186 \mathrm{~Hz}$ out weight all of the frequencies in terms of their occurrence, and among the three frequencies, $185 \mathrm{~Hz}$ has a high amplitude. When the boat is in idle state, the sound pressure level inside the engine room reaches $103 \mathrm{~dB}$, and when the boat starts to disembark, the sound pressure level reaches up to $119 \mathrm{~dB}$ of sound pressures. The result of this study greatly contributes to the design of a resonator for noise energy harvester. 


\section{REFERENCES}

[1] Bacosa Jr CA, Baldovino MAP. (2018). Sound Energy: An Electric Source of Noise Pollution Based Power Bank. KnE Social Sciences 3:221. DOI: 10.18502/kss.v3i6.2382

[2] Farghaly YA, Hemeida FAA, Salah S. (2019). Noise utilization as an approach for reducing energy consumption in street lighting. PLoS One 14:e219373

[3] U.S. Department of Health and Human Services National Institutes of Health. (2014). Noise-Induced Hearing Loss. In: National Institute on Deafness and Other Communication Disorders. Retrieved from https://www.nidcd.nih.gov/health/noise-inducedhearing-loss. Accessed 8 Oct 2019

[4] Garg M, Gera D, Bansal A, Kumar A. (2015). Generation of electrical energy from sound energy. In: 2015 International Conference on Signal Processing and Communication (ICSC). IEEE, pp 410-412

[5] Agarwal A, Lang J. (2005). Foundations of Analog and Digital Electronic Circuits, 1st Edition. Morgan Kaufmann

[6] Gupta A, Goel V, Yadav V. (2014). Conversion of Sound to Electric Energy. International Journal of Scientific \& Engineering Research 5:2146-2149

[7] Fang LH, Hassan SIS, Rahim RA, Isa M, Ismail BB. (2017). Exploring Piezoelectric for Sound Wave as Energy Harvester. Energy Procedia 105:459-466. DOI: 10.1016/j.egypro.2017.03.341

[8] Berg RE. (2004). The Physics of Sound, 3rd Edition. Benjamin Cummings

[9] Usher MJ, Keating DA. (1996). Sensors and Transducers: Characteristics, Applications, Instrumentation, Interfacing. Macmillan Education UK

[10] Zheng S. (2019). FFT in Matlab

[11] Borandağ E. (2019). Markov Model Based Real Time Speaker Recognition using K-Means, Fast Fourier Transform and Mel Frequency Cepstral Coefficients. Celal Bayar Üniversitesi Fen Bilim Derg 287-292. DOI: 10.18466/cbayarfbe.556936

[12] Li XG, Yao MF, Yang JN. (2012). Speech recognition approach based on speech feature clustering and HMM. J Comput 7:2269-2275. DOI: 10.4304/jcp.7.9.2269-2275

[13] Neel J. (2005). Cluster analysis methods for speech recognition. Dep Speech, Music Hear R Inst Technol S-100 44 Stock

[14] Ville Pulkki, Karjalainen M. (2015). Communication Acoustics: An Introduction to Speech, Audio and Psychoacoustics. John Wiley \& Sons 